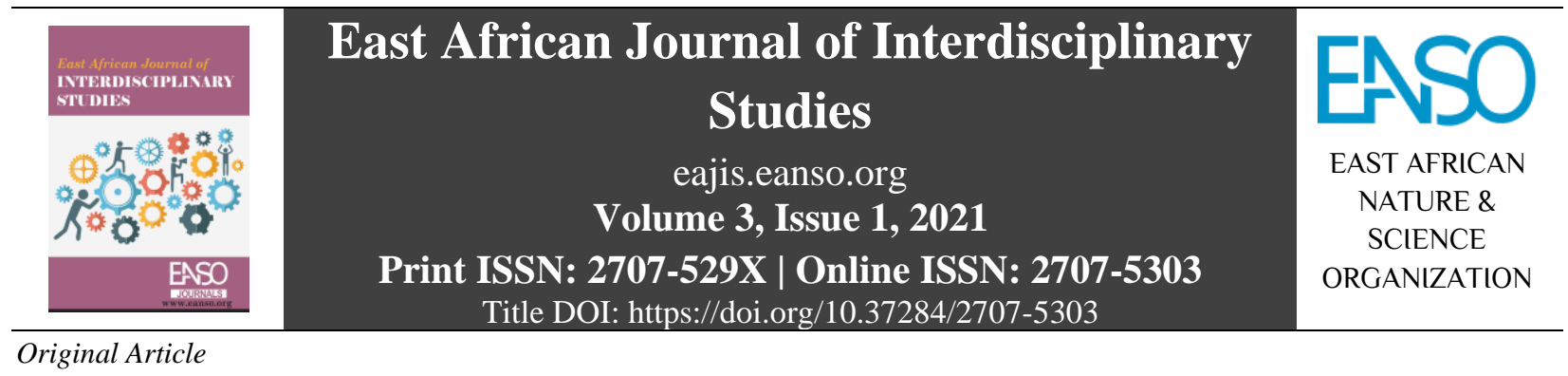

\title{
Allocative Inefficiency of General Hospitals in Poor Countries: A Case Study of Uganda
}

Dr. Max Ajanga $(P h D)^{1 *}$

${ }^{1}$ Department of Economics and Statistics, Kyambogo University, P. O. Box 1 Kyambogo, Kampala.

*ORCID: https://orcid.org/0000-0002-9159-5809;Author for Correspondence email: mxajanga@kyu.ac.ug

Article DOI: https://doi.org/10.37284/eajis.3.1.346

\section{Date Published: ABSTRACT}

15 June 2021 The increasing costs of healthcare arising largely from the growing population and emergence of non-communicable diseases have exerted pressure on

Keywords: healthcare budgets in poor countries. With a funding gap of $7 \%$ to realize WHO recommended target of 15 percent of GDP in Uganda, there is a need for

Efficiency, hospitals to be efficient in allocation of financial resources in order to provide Drugs, the required level of healthcare services. Most studies on Uganda have focused on the technical inefficiency of general hospitals and evidence on their allocative Medical staff, inefficiency is limited. Understanding the sources of inefficiency in the patients, allocation of finances in general hospitals in Uganda is important to improve their performance. The purpose of this study was to determine the allocative hospitals, inefficiency of the general hospitals in Uganda in order to provide a source of Utilities. misuse of public allocations to a particular general hospital. Panel data from 22 general hospitals for the period 1997-2007 were used. Allocative inefficiency was estimated using Stochastic Frontier Analysis. The findings show that general hospitals are systematically allocatively inefficient in distributing the public funds given to them. The allocative inefficiencies value is high on payments of employee benefits (34.8 percent), followed by the purchase of drugs (29.2\%) and lastly, costs on utilities like electricity and water (14.1\%). To address the existing allocative inefficiencies, general hospitals in Uganda can improve the process of hiring of labour and management of staff payroll; monitor procurement of drugs, and reduce wastages in the use of utilities.

\section{APA CITATION}

Ajanga, M. (2021). Allocative Inefficiency of General Hospitals in Poor Countries: A Case Study of Uganda. East African Journal of Interdisciplinary Studies, 3(1), 128-143. https://doi.org/10.37284/eajis.3.1.346

\section{CHICAGO CITATION}

Ajanga, Max. 2021. "Allocative Inefficiency of General Hospitals in Poor Countries: A Case Study of Uganda". East African Journal of Interdisciplinary Studies 3 (1), 128-143. https://doi.org/10.37284/eajis.3.346.

\section{HARVARD CITATION}

Ajanga, M. (2021) "Allocative Inefficiency of General Hospitals in Poor Countries: A Case Study of Uganda", East African Journal of Interdisciplinary Studies, 3(1), pp. 128-143. doi: 10.37284/eajis.3.1.346. 


\section{IEEE CITATION}

M. Ajanga, "Allocative Inefficiency of General Hospitals in Poor Countries: A Case Study of Uganda”, EAJIS, vol. 3, no. 1, pp. 128-143, Jun. 2021.

\section{MLA CITATION}

Ajanga, Max. "Allocative Inefficiency of General Hospitals in Poor Countries: A Case Study of Uganda". East African Journal of Interdisciplinary Studies, Vol. 3, no. 1, Jun. 2021, pp. 128-143, doi:10.37284/eajis.3.1.346.

\section{INTRODUCTION}

Healthcare is one of the basic human needs which is very limited in supply in poor countries and requires allocations and institutions to organise those allocations. Hospitals form a 'hub' of healthcare. They need a constant, adequate and timely supply of inputs for this purpose and yet resources are scarce. To reduce the effect of scarcity on the production of healthcare services, hospital allocative efficiency is key. This study puts an emphasis to scrutinise the allocative inefficiency of the general hospital subsector in Uganda because; first, general hospitals use up to 60 percent of resources allocated to the hospital sector in Uganda and secondly, allocative efficiency is a primary basis upon which hospitals can access inputs to produce healthcare.

The dependent variables are expenditure on inputs of general hospitals which are employee benefits, drugs and utilities. The independent variables are the size of inputs, expected hospital outputs and level of allocative inefficiency. The theoretical framework concerns the efficiency of allocating budgetary votes as a proportion of the total cost to a given set of inputs used in the provision of healthcare to an observed set of patients. The dependent variable is the proportion of total costs spent on a given input for example labour input, utilities and drugs and medical supplies. The independent variables are the amounts of units of these inputs employed by the hospitals (number of doctors, nurses, other employees and beds) and the number of patients treated plus the size of inefficiency. This can be expressed as in Lave and Lave (1984) as follows;
$\frac{T C_{i t}}{P_{i t} X_{i t-1}}=f\left(X_{i t-1}, Y_{i t-1}, \varepsilon_{t}\right)$

Where; $\mathrm{TC}_{\mathrm{it}}=$ Total cost of production by General Hospitals $i$ at time $t, i=1,2, \ldots$ and $t=1998--; P_{i t}$ $=$ Unit price of $\mathrm{x}$ at current year; $\mathrm{X}_{\mathrm{it}-1}=$ Number of units of inputs used in the previous year; $\mathrm{Y}_{\mathrm{it}-1}=$ Output produced by General Hospitals $i$ in the previous year; $\varepsilon_{\mathrm{t}}=$ Error term that will account for allocative inefficiency in the current budget year.

Equation 1 is explained since the budget estimates for the current year are drawn from expenditures on inputs used in the previous year. The error term will be explained using the Stochastic cost frontier analysis to be explained in the methodology. The existence of errors during the allocation will tantamount to waste or loss to the hospital sector since the finances that would have been used to buy inputs that can optimise patients' welfare are used for inputs that do not improve health. According to Uganda Health Accounts (2017/18), 64.3 percent of government current health expenditure takes place in the hospitals, of which 38 percent was spent in the general hospitals. Most studies on Uganda have focused on technical efficiency. For example, Yawe (2006) looked at technical efficiency and total factor productivity of district hospitals in Uganda using Data Envelopment Analysis (DEA)., Yawe and Kavuma (2008) further looked at technical efficiency in the presence of desirable and undesirable outputs: a case study of district referral hospitals in Uganda. He used modified DEA analysis. In 2010, Yawe also did hospital performance evaluation in Uganda using a superefficiency data envelopment analysis model. Mujasi and Kirigia (2016) studied "how efficient were referral hospitals in Uganda using DEA and Tobit

129 | This work is licensed under a Creative Commons Attribution 4.0 International License. 
regression analysis". Others studies include that of Nannyonjo and Okot (2013). These studies explain that, technical efficiency measures 'by how much hospital outputs can be increased from given inputs, or by how much can inputs be contracted in production of given outputs relative to others operating on the production possibility frontier'.

Worthington (2004) reviewed 38 studies and found out that 70 percent measured technical efficiency and 30 percent measured allocative efficiency, 68 percent used hospitals, 10 percent used nursing homes, 5 percent health management organisations while 68 percent used DEA and 32 percent used Stochastic Frontier Analysis (SFA).

The theoretical framework for this study follows from Wei et al. (2018) who studied hospital efficiency and utilisation of high technology medical equipment. They estimated hospital cost inefficiency scores of 131 hospitals in China 20092013 through stochastic frontier analysis. They used panel data analysis and a number of assumptions including choice of functional form (e.g., translog functions) and the variables entered in the analysis) expressed as;

$\ln \frac{T C_{h t}}{p_{i} x_{i h t}}=\beta_{i}+\sum_{j-1}^{n} \beta_{i j} \ln x_{i h t}+$
$\sum_{r-1}^{m} p_{r i} \ln y_{r h t}+\emptyset_{f t} \ln f_{h t}+\mu_{i h t}$

[2]

Where all variables are logged (translog) to generate a second-order cost function. $\mathrm{TC}_{\mathrm{ht}}=$ total recurrent costs in hospital $\mathrm{h}$ at time $\mathrm{t}, \mathrm{y}=\left(\mathrm{y}_{1}, \ldots \ldots \ldots . ., \mathrm{y}_{\mathrm{m}}\right)$ is an output vector, $\mathrm{x}=\left(\mathrm{x}_{1}, \ldots \ldots \ldots, \mathrm{x}_{\mathrm{n}}\right)$ is a variable input vector, $f$ is fixed inputs (like the number of beds), $t$ is a time variable measured in years, $h=$ $1, \ldots \ldots ., 131$ denotes hospitals; $p_{i}$ is a unit price of input $i ; \beta_{i}$-intercept for input $i ; \beta_{i j}=$ measures the extent to which a change in input $x$ affects the proportional allocation to $\mathrm{x}$ hired; $\mathrm{P}_{\mathrm{ri}}=$ measures the extent to which changes in the size of hospital output $\mathrm{r}$ affects the allocation to input $\mathrm{x}$ and $\phi_{\mathrm{fi}}=$ measures the extent to which changes in fixed factor input $\mathrm{f}$ affects allocations to factor $\mathrm{i}$, and $\mu_{\text {iht }}$ is a disturbance term or residual.

The primary dependent variables of this study are proportional allocations to three key areas of drugs, employee benefits and utilities and consumables and key explanatory variables are inputs, output and allocative inefficiency which was derived using SFA. SFA measures inefficiency at providers' or payers' level. Hospitals with readily available inputs are allocative efficient and are expected to attract patients.

The SFA technique of inefficiency measurement was first proposed by Meeusen and van Den Broeck (1977) to estimate the technical inefficiency of French firms. Aigner, Lovell and Schmidt (1977) formulated and estimated production frontier models using data from the US primary metals industry across 28 states and running Ordinary Least Squares (OLS) regressions. Kumbhakar and Lovell (2003) explained how stochastic frontier analysis can be used to specify inefficiency terms in both production- and cost-frontier models. Following from the works of Kumbhakar and Lovell (2003) allocative inefficiency can be derived in the cost function expression specified as;

$$
\begin{aligned}
& \ln \left(c_{i t}\right)=\beta_{0}+\beta_{q} \ln \left(q_{i t}\right)+\sum_{j-1}^{k} \beta_{j} \ln \left(p_{j i t}\right)+ \\
& v_{i t}+u_{i t}
\end{aligned}
$$

Where $\mathrm{q}_{\mathrm{it}}$ is output, $\mathrm{c}_{\mathrm{it}}$ is cost, the $\mathrm{p}_{\mathrm{jit}}$ are input prices, and $u_{i t}$ is allocative inefficiency of hospital $i$ at time t. $u_{i t}$ is positive because allocative inefficiency is assumed to increase the costs.

O'Donnell and Nguyen (2011), explained that SFA parametric modelling technique accounts for measurement errors, omitted exogenous variables and other sources of statistical noise. The data used in this study may have a number of measurement errors, for example, combined use of a number of cases treated and all exogenous variables like timely releases of funds, corruption, market price fluctuation and location is omitted, hence the ideal use of SCFA.

130 | This work is licensed under a Creative Commons Attribution 4.0 International License. 
In this study, the use of SFA has taken care of this problem by establishing general hospitals' internal allocative inefficiencies in order to ascertain how well a given hospital could have done and got the mean allocative inefficiency of each hospital to allow for comparisons to other general hospitals.

Eakins (1991) measured the allocative inefficiency of 331 hospitals using non-minimum cost function in the US and found out that overcapitalisation and underemployment of physicians increase hospital costs by about 5 percent. Hospital care expenditures are about 4.5 percent of the gross national product. $\mathrm{He}$ also found out that at the means of data, the cost is 5.3 percent above minimum cost. He attributed this to the underemployment of doctors as the major factor contributing to allocative inefficiency in hospitals.

\section{The Research Problem}

Fuelled by rising health care expenditures, greater demand for healthcare due to the growing population, emerging non communicable diseases (NCD) and limited annual expenditure of less than 8 percent of the GDP, attention should be turned towards institutional health care efficiency and its measurement. Measures of inefficiency help identify the different sources of inefficiency and can be used in hospital performance monitoring. Many studies in Uganda have documented technical inefficiency. Limited research has been done on the allocative inefficiency of general hospitals. No studies have used SFA techniques to estimate allocative inefficiency of hospital institutions using data from developing countries like Uganda.

Therefore, limited information about the size of allocative inefficiency on the recurrent expenditure of general hospitals is available. There are shortages in the supply of medicines and utilities. Hence high undesirable outputs like annual Under-five
Mortality Rate (U-5MR 64/1000) and annual Maternal Mortality ratio (MMR 336/100000) still above Millennium sustainable development goals (MOH, 2017).

\section{Research Objective}

Specifically, the study intended to determine allocative inefficiencies of general hospitals in Uganda. The assumption here is that general hospitals' budget process leads to accurate allocations that rationally seek to optimise the healthcare of the patients. Errors arising from wrongful budgetary allocations or wrong internal distributions of money to various inputs constitute inefficiency. This study estimated these errors as allocative inefficiency using the SFA procedure.

\section{Conceptual Framework}

The major concern of every economist is the careful or efficient use of scarce resources to produce valued firms' outputs. General hospital's allocative efficiency is the ability of hospital managers to secure adequate inputs at given costs to produce expected outputs or number of treatments. These hospitals belong to the public. Implying that the resources used by the general hospitals come mainly from the government budget process. The payers, therefore, wish to see their financial contributions used to maximise treatments. A general hospital will be allocatively inefficient if it produces treatments with low-cost-effectiveness. In the conceptual framework (Figure 1.), the concept of costs is inherent to the existence of a hospital as it is the only way a hospital gets the supply of inputs to enhance healthcare service delivery. Each general hospital takes its own expenditure decisions on how to use its money in order to meet the treatment demands of its patients. The key costing areas include employee benefits, drugs and medical supplies and utilities and consumables. 


\section{Figure 1: Conceptual Framework}

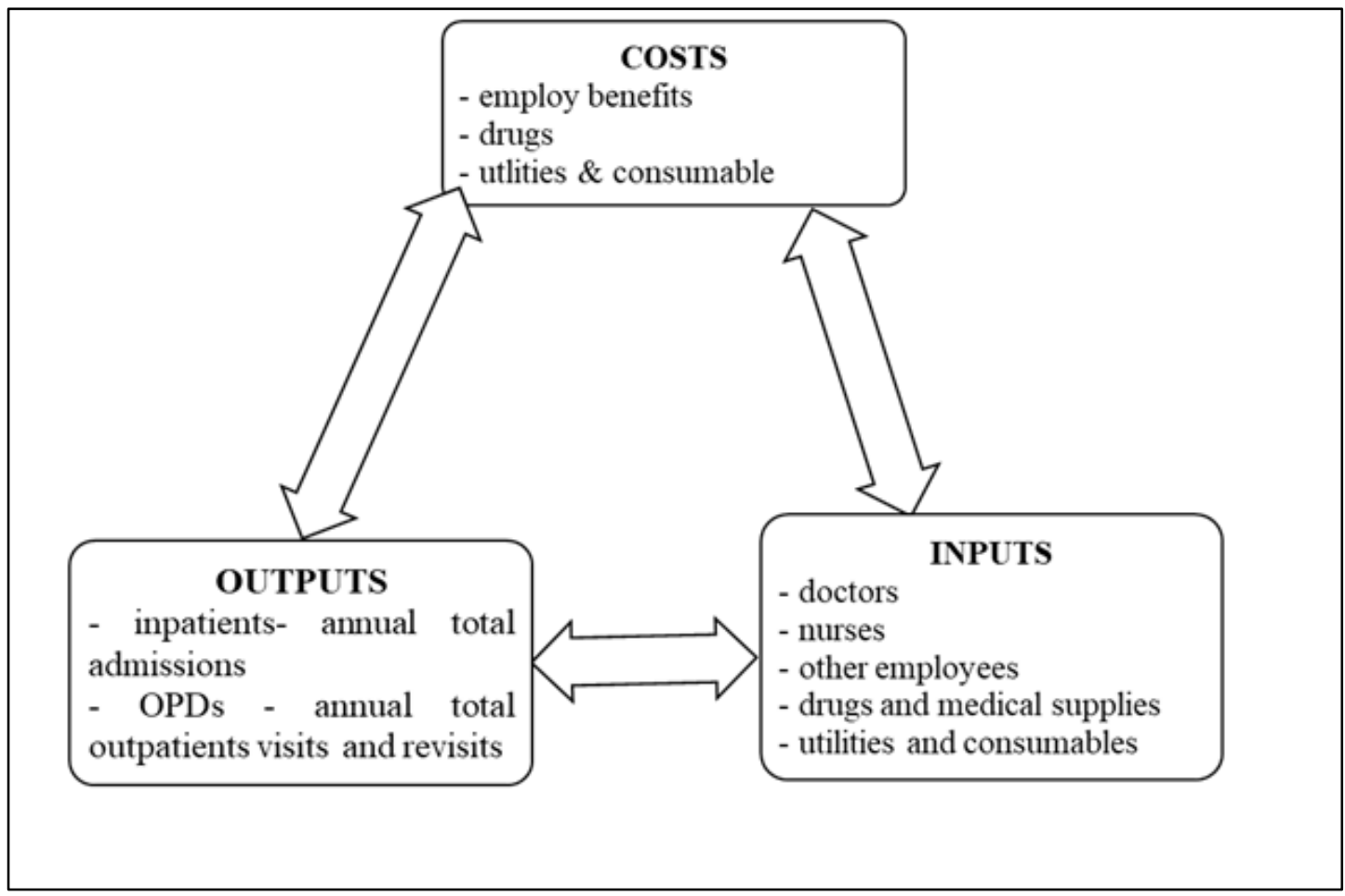

The study included wage employee benefits like allowances, welfare, consultancies, travel, workshops or seminars, staff training, medical expenses, death benefits and funerals, compensations and entertainment. These are expenses incurred by the general hospitals as employees provide day-to-day healthcare delivery. These benefits provide an incentive for the hire of hospital human resources. The bigger these benefits the more available the labour is.

The second component of costs arises towards the acquisition of drugs. Drugs and medical supplies are supplies of medical care goods and services and the purchase of drugs. General hospitals requisition for drugs from National Medical Stores (NMS) following their drug lines or votes. The hospital's task is to make requests for drug mix according to the case mix.

Utilities and consumables include expenditure on water, electricity, advertising and public relations, books, periodicals and newspapers, computer supplies and IT services, printing, stationery and photocopying, telephone, postages and couriers.

\section{DATA AND METHODS}

\section{Sampling Technique, Sample Size and Data Collection}

This study was a panel data study. Secondary data was collected from 22 general hospitals over a period of twenty years between 1997 and 2017. The source was published government documents; audited final books of accounts in the Auditor general's office, district transfers for health services from MOPFED, district final books of accounts, general hospitals' records on budget estimates (revenues and expenditures), admissions, OPD visits and Annual Health Sector Performance reports for the period 1997/98 FY to 2017/18 FY.

The unit of analysis in this study was a general hospital. The sample was selected by dividing the country into four regions or strata. Northern, Eastern, Central and Western regions. From each

132 | This work is licensed under a Creative Commons Attribution 4.0 International License. 
region (except the Eastern region which was so big) five general hospitals were purposefully selected depending on the characteristic of homogeneity to ensure continuity and uniformity of data. The sample size of twenty-two general hospitals was used as shown in Table 1.

Table 1: Sample of general hospitals by region

\begin{tabular}{ll}
\hline Region & Name of General Hospital \\
\hline North & Adjumani, Apac, Moyo, Nebbi, Kitgum \\
East & Aturtur, Bugiri, Iganga, Kapchorwa, Moroto, Pallisa, Tororo \\
Central & Mpigi, Kawolo, Kiboga, Mubende, Rakai, \\
West & Bundibugyo, Bwera, Kisoro, Masindi, Kibale \\
\hline
\end{tabular}

The general hospitals in Table 1 existed as district hospitals by 1997/98 financial year. This means that allocations are comparable since they have an average size of 108 beds and they follow the same budget procedure. It's therefore reasonable to assume homogeneity in the range of decisions taken by each unit in allocating a given amount of money to a given health care input it hires.

\section{The Description of Variables}

General hospitals use a number of inputs (human and non-human) in the process of providing services

Table 2: Description of variables that are aimed at meeting the needs of patients and contribute to a healthier population. Estimation of allocative inefficiency uses the choice of inputs and outputs that hospitals involved in their production processes. The variables are derived from various items or activities upon which the general hospitals spend their revenue. Some of the variables used in this study were also used by Yawe (2006) in analysing technical efficiency and total productivity of district hospitals in Uganda as shown in Table 2.

\begin{tabular}{|c|c|}
\hline $\begin{array}{l}\text { Variable name } \\
\text { Inputs }\end{array}$ & Description and measurement of input and output variables \\
\hline Beds & (beds) Total number of beds in the hospital \\
\hline $\begin{array}{l}\text { Employ } \\
\text { benefits }\end{array}$ & $\begin{array}{l}\text { (empben)- general hospital expenditure allowances, medical care, burial expenses, } \\
\text { welfare, uniforms, meals, travel, entertainment, etc. }\end{array}$ \\
\hline $\begin{array}{ll}\text { Drugs and } \\
\text { medical } \\
\text { supplies }\end{array}$ & (drmeds)-general hospital's expenditures on drugs and medical supplies \\
\hline $\begin{array}{l}\text { Utilities and } \\
\text { consumables }\end{array}$ & $\begin{array}{l}\text { (util)-expenditure on electricity, water, telephone, email, fax, postage, newspapers, } \\
\text { cleaning wards, printing, stationery, advertising and public relation }\end{array}$ \\
\hline Doctors & $\begin{array}{l}\text { (drs- total number of doctors, gynecologists, dental surgeons and general doctors } \\
\text { employed in general hospital }\end{array}$ \\
\hline Nurses & $\begin{array}{l}\text { (nrs)- total number of nurses-midwives, enrolled nurses, registered nurses, clinical } \\
\text { officers, laboratory technicians, radiographers. }\end{array}$ \\
\hline $\begin{array}{l}\text { Other } \\
\text { employees }\end{array}$ & $\begin{array}{l}\text { (otheremp)-number of other employees- drivers, administrators, support staff, guards, } \\
\text { records assistant }\end{array}$ \\
\hline Outputs & Total number treated in either inpatient or OPD \\
\hline $\begin{array}{l}\text { Total } \\
\text { admissions }\end{array}$ & (toadm)- Total annual admissions \\
\hline $\begin{array}{ll}\text { Out } & \text { patients' } \\
\text { visits }\end{array}$ & out patients visits and revists \\
\hline
\end{tabular}

133 | This work is licensed under a Creative Commons Attribution 4.0 International License. 
Input Variables: There are basically five input variables in this study and they include, doctors, nurses, other employees, beds and drugs and medicines. The study uses absolute numbers to estimates labour inputs and beds. By classifying labour into different categories, many studies recognise the differing skill requirements for nurses, physicians, administrators, and support staff (Peacock et al., 2001; Wei et al., 2018). The input of labour is often measured in terms of staff numbers. The weakness with this approach of measuring employment is that it reveals little about the use of the workforce, as it obscures the mix of full-time, part-time and casual workers as well as staff working overtime (Caballer-Tarazona et al., 2009). The number of hours worked is the preferred unit of measurement. But there are no records in general hospitals where work hours are kept for each labour input category. To solve this problem, the study uses the annual total cost on labour as a proportion of the total annual recurrent expenditure of the general hospitals (average variable cost).

Drugs, medical supplies and utilities and consumables are also used as inputs in the production of healthcare. It is common to aggregate purchased drugs and medical supplies as one cost variable (Caballer-Tarazona et al., 2009; Wei et al., 2018) and utilities and consumables as the other cost variable. This study adopted the same procedure because quantity data on each drug, medical supplies and utilities are scarce or are not available for the whole study period. The dependent variable was drug and medical expenditure allocated in the budget as a proportion of total recurrent expenditure.

Beds are used as a proxy for capital inputs because of a lack of reliable measures of the value of other assets like premises, machinery and equipment. Capital input refers to the service flow derived from a durable capital stock (Rodríguez-Álvarez, 2004). Under this assumption, the service flow is directly proportional to capital stock quantity. The number of beds is the most used capital stock variable in hospital studies (Nabukeera, 2016; RodríguezÁlvarez, 2004). Other capital stock variables that can be used are the numbers of birthing rooms and surgical operating rooms. This study uses the number of beds as a proxy for capital due to data limitations.

Output variables: These include total annual admissions and total outpatient department attendances. It's expected that inpatients' and OPDs visits in the previous year will influence the budget for this year's expenditure. When measuring output, the recommendations of Battese and Coelli (1995) and used by Bojnec et al (2015) were followed. They recommended that "output must be defined as unified aggregated business impact". The inpatient care was therefore measured as total annual cases treated after admissions. This study did not disaggregate admissions by case mix, because its concern was on allocative but not technical inefficiency. Outpatients' department attendances include the annual sum of both new cases and reattendances. These output variables were also used by Carey (1997) when estimating hospital cost functions, Mutter, Rosko and Wong (2008) when measuring inefficiency of hospitals as affected by controlling for quality and patients burden of illness, Caballer-Tarazona et al. (2010) while measuring the efficiency of hospital performance, Hamidi (2016) while measuring efficiency of government hospitals in Palestine.

\section{Selection of Empirical Model for Allocative Inefficiency Estimation}

Carey (1997) observed that a number of hospital cost functions have relied on single-year cross sectional data, and yet there exist unobservable systematic differences among hospitals like, managerial differences whose effect can be felt over time. The use of observations collected over a period (panel data) may help take into consideration these differences. The use of panel data requires that a model be selected that best fits the available data. To do this one needs to consider a number of

134 | This work is licensed under a Creative Commons Attribution 4.0 International License. 
East African Journal of Interdisciplinary Studies, Volume 3, Issue 1, 2021

Article DOI: https://doi.org/10.37284/eajis.3.1.346

econometric issues some of which are discussed below.

\section{Fixed or Random Effects Analysis}

The concern here was whether to treat inefficiency terms as time-variant or invariant. Each general hospital has its own individual characteristics that may influence the predictor variables (for example being located in the North, having big number of poor populations surrounding it, etc.). The assumption is that these characteristics may impact or bias the predictor variables and there is a need to control for this in order to assess the predictors' net effect.

The other assumption is that those time-invariant characteristics are unique to the hospital and should

Table 3: Hausman fixed or random test output not be correlated with other hospitals' characteristics. That means the hospital's error term and the constant (which captures her characteristics) should not be correlated with those of others. If the error terms are correlated then the Fixed Effect model is not suitable since inferences cannot be correct and one needs to model that relationship (probably using random-effects).

To decide between fixed or random effects one runs a Housman test where the null hypothesis is that the preferred model is random effects versus the alternative fixed effects. It tests whether the unique errors $\left(u_{i}\right)$ are correlated with the regressors, the null hypothesis is they are not. The output is shown in Table 3.

\begin{tabular}{lllll}
\hline Coefficients & (b) Fixed & (B) Random & (b-B) Difference & Stand. Error \\
\hline ldrs & -0.0446 & 0.0630 & -0.1077 & - \\
lnrs & 0.1870 & -0.3666 & 0.5536 & 0.2415 \\
lotheremp & -0.5068 & 0.2204 & -0.7272 & 0.2930 \\
ltoadm & -0.0214 & 0.0168 & -0.0382 & 0.0489 \\
lopd & -0.0306 & 0.0648 & -0.0954 & - \\
lbeds & 0.5886 & -0.2290 & 0.8176 & 0.3837 \\
\hline
\end{tabular}

Test: Ho: difference in coefficients not systematic chi2(6) $=16.35 ; \quad$ Prob $>$ chi $2=0.0120$

Decision: Since Prob $>$ chi2 $=0.0120$ is less than 0.05 then RE is suited for analysis. The output of the test indicates that RE analysis is more suited for this data as compared to FE analysis.

This decision permits one to use GLM procedures to fit the data in the analysis. However, being Panel data, there was a need to go further and establish whether there is no cross-sectional interdependence or contemporaneous correlations amongst panels by carrying out Breusch-Pagan LM test. But this cannot be done, because according to Baltagi (2005), the use of Breusch-Pagan LM test of crosssectional dependence or serial correlation is possible in macro panels with long time series (2030 years). Serial correlation causes the standard errors to be small and higher R-squared. They observe that this is not much of a problem in micro panels (few years and large number of cases). And in micro panels with short time periods, what is important is correlations across units (e.g., GHs). It tests whether there was cross-sectional dependence across response units. This was tested using the Pasaran CD test as shown below.

\section{Pasaran Cross-Sectional Dependence (CD) Test}

Pasaran CD test was used to test whether the residuals are correlated across GHs. This is also called contemporaneous correlation. The null

135 | This work is licensed under a Creative Commons Attribution 4.0 International License. 
East African Journal of Interdisciplinary Studies, Volume 3, Issue 1, 2021

Article DOI: https://doi.org/10.37284/eajis.3.1.346

hypothesis was that residuals are not correlated and the results are:

Pasaran's test of cross-sectional independence $=$ 1.021 and $\operatorname{Pr}=0.3072$

Decision: Since Pasaran's test of cross-sectional independence is -1.021 and $\operatorname{Pr}=0.3072$ (i.e.pr > $0.05)$ then there is cross-sectional dependence. The presence of cross-sectional dependence affects the first-order properties of estimators (that is, unbiases and consistency) and therefore limits the use of OLS procedure, hence the need to use GLM procedures.

\section{Testing for Heteroscedasticity}

A test for Heteroscedasticiy was done and the result shows a Modified Wald test for GroupWise Heteroscedasticity in the fixed effect regression model. The null is $\mathrm{H}_{0}$ : sigma (i $)^{\wedge} 2=\operatorname{sigma}^{\wedge} 2$ for all $\mathrm{i} ; \operatorname{chi} 2(22)=181.09$ and Prob. $>$ chi $2=0.0000$

Decision: The null is Homoscedasticity (or constant variance). Above we reject the null and conclude Heteroscedasticity. So we shall use a Heteroscedastically-robust estimator for the covariance matrix of the regression parameters by applying STATA command xtgls syntax.

\section{Selecting between GLM and Frontier Analysis}

Table 4: Akaike's information criterion and Bayesian information criterion

\begin{tabular}{lllll}
\hline Model & null & df & AIC & BIC \\
\hline glm & -184.9436 & 7 & 383.8872 & 407.6426 \\
frontier & -161.4446 & 9 & 340.8892 & 371.4318 \\
\hline
\end{tabular}

Following the findings in Table 4, the study went ahead to estimate allocative inefficiency of GHs using Stochastic Cost Frontier Analysis (SCFA). The SCFA model used here was used by Jondrow et al. (1982) to estimate hospital cost inefficiency in North Holland, used by Yong and Harris (1999), to measure the efficiency of hospitals in Victoria under case-mix funding, and also used by Kumbhakar and Lovell (2003), Mutter et al. (2008) to measure hospital cost inefficiency in the U.S., RodríguezÁlvarez et al. (2004) to measure allocative inefficiency of public hospitals in Spain, Choi et al. (2017) to measure the efficiency of US hospitals (using data panels between 2001-2011).
The SCF analysis comprises error term that separates inefficiency effect from statistical noise, and can be specified as;

$\ln C_{i t}=\ln C\left(p_{i t-1}, q_{i t-1}, \theta\right)+v_{i t}+u_{i t}$

Where $\mathrm{C}_{\mathrm{it}}$ is the observed cost, $\mathrm{p}_{\mathrm{it}-1}$ is a vector of input prices in the previous year, $\mathrm{q}_{\mathrm{it}-1}$ is a vector of output produced in the previous year, $\theta$ is a vector of technology parameters, $u_{i t}$ is a non-negative stochastic error capturing the effects of inefficiency and $v_{i t}$ is asymmetric error component.

The theoretical input cost share equations for general hospital $\mathrm{h}$ over time $\mathrm{t}$ is given as in Wei et al. (2018).

Table 5: Selecting from Half normal, Exponential and Truncated normal

\begin{tabular}{llll}
\hline Variables & Hnormal & exponential & tnormal \\
\hline ldrs & $0.2022^{* * *}$ & 0.0918 & 0.2152 \\
lnrs & $-0.2664^{* *}$ & -0.1513 & $-0.2694 * * *$ \\
lotheremp & $0.6786^{* * *}$ & $0.3352^{* * *}$ & $0.6762^{* * * *}$ \\
ltoadm & 0.1629 & 0.0852 & 0.1975 \\
\hline
\end{tabular}

136 This work is licensed under a Creative Commons Attribution 4.0 International License. 
East African Journal of Interdisciplinary Studies, Volume 3, Issue 1, 2021

Article DOI: https://doi.org/10.37284/eajis.3.1.346

\begin{tabular}{llll}
\hline Variables & Hnormal & exponential & tnormal \\
\hline lopd & -0.1799 & -0.0363 & -0.1780 \\
lbeds & 0.1732 & 0.0108 & 0.1948 \\
cons & $-2.8697^{* * *}$ & -2.8603 & -3.2907 \\
lnsig2v cons & $-13.2708^{* * *}$ & -3.3406 & \\
lnsig2u cons & -0.1640 & -1.2694 & \\
mu cons & & & 0.3551 \\
ilgtgamma cons & & & $12.9149 * * *$ \\
lnsigma2 cons & & & -0.3326 \\
\hline
\end{tabular}

The coefficients for explanatory variables, for inefficiency distribution $\left(\mu_{\mathrm{iht}}\right)$, the constant, lnsig2 $\mathrm{v}$ and lnsig $2 \mathrm{u}$ under half-normal distribution are bigger in absolute terms and many are statistically significant at $1 \%$ level of significance. The implication is that half normal distribution best explains the influences of these variables or GHs characteristics to changes in cost allocations or resulting allocative inefficiency of general hospitals. Analysis was therefore done using half normal frontier analysis and log transformed values of independent variables.

In this study, the variable inputs comprised Drs, Nrs and otheremp, fixed input is represented by the number of beds in general hospital and the output vector comprises toadm and OPD. Allocations are done on drugs and medical supplies (drmeds), utilities and consumables (util) and labour inputs get employee benefits (empben). This gives rise to estimation of system of three equations;

$\ln d r m e d s_{h t}=\beta_{0}+\beta_{1} \ln \operatorname{Drs}_{h t-1}+\beta_{2} \ln N r s_{h t-1}+\beta_{3} \ln$ otheremp $p_{h t-1}+$

$\alpha_{1} \ln$ toadm $_{h t-1}+\alpha_{2} \ln O P D_{h t-1}+\varepsilon \ln$ beds $s_{h t-1}+u_{h t}$

ln empben ent $_{h t}=\beta_{0}+\beta_{1} \ln \operatorname{Drs}_{h t-1}+\beta_{2} \ln N r s_{h t-1}+\beta_{3} \ln$ otheremp ${ }_{h t-1}+$

$\alpha_{1} \ln$ toadm $_{h t-1}+\alpha_{2} \ln O P D_{h t-1}+\varepsilon \ln$ beds $s_{h t-1}+u_{h t}$

$\ln u t i l_{h t}=\beta_{0}+\beta_{1} \ln \operatorname{Drs}_{h t-1}+\beta_{2} \ln N r s_{h t-1}+\beta_{3} \ln$ otheremp $_{h t-1}+$ $\alpha_{1} \ln$ toadm $_{h t-1}+\alpha_{2} \ln O P D_{h t-1}+\varepsilon \ln$ beds $_{h t-1}+u_{h t}$

Note: The value of the coefficients will vary for each model (4.1-4.3). The values of the coefficients in regression with multiple independent variables, tell you how much the dependent variable is expected to increase when that independent variable increases by one, holding all the other independent variables constant.

The error terms $u_{i}$ and $v_{i}$ were assumed to follow any of the three distributional assumptions on the inefficiency component as follows;

- The Half-Normal Distribution (hnormal): the half-normal case imposes the following restrictions on the error term:

$v_{i}=i i d\left(0, \sigma_{v}^{2}\right){ }_{i}=i i d N^{+}\left(0, \sigma_{u}^{2}\right)$ $v_{i}$ and $u_{i}$ are distributed independently of each other and of the Regressors.

- Truncated-Normal distribution (tnormal): distributed with truncation point at 0 and imposes the following restrictions on the error term:

$$
v_{i}=i i d\left(0, \sigma_{v}^{2}\right) \quad u_{i}=i i d N^{+}\left(\mu, \sigma_{u}^{2}\right)
$$

$v_{i}$ and $u_{i}$ are distributed independently of each other and of the Regressors, and $\mu$ is nonzero mean for $u_{i}$

- Exponential: the $\mathrm{u}_{\mathrm{i}}$ are independently exponentially distributed with variance $\sigma_{u}^{2}$

137 | This work is licensed under a Creative Commons Attribution 4.0 International License. 
All input and output variables were transformed into their corresponding log values to get equations (4.14.3). This is so as to make highly skewed distributions less skewed and patterns in the data more interpretable. The distributional assumption on the inefficiency component $\left(\mathrm{u}_{\mathrm{ht}}\right)$ of the error term according to Battese and Coelli (1995) inefficiency model was specified as:

$$
\mu_{h t}=\delta_{0}+\sum_{i=1}^{22} \delta_{i} z_{i}+w_{i}
$$

Where $\mathrm{u}_{\mathrm{i}}$ is the inefficiency, $z_{\mathrm{i}}$ is the vector of hospital variables (general hospital characteristics) that are likely to affect efficiency, $\delta$ 's are the parameters, and $\mathrm{w}_{\mathrm{i}}$ is the error term of the efficiency model. As the dependent variable in equation (4.5) is defined in terms of allocative inefficiency, a hospital variable associated with the positive (negative) coefficient will have a positive (negative) impact on allocative inefficiency.

\section{RESULTS}

The preferred model was based on the comparison of output of distributions of error terms shown in the Table 6; (Greene, 2003; Mutter et al., 2008). The estimates of allocative inefficiency given in three models 4.1, 4.2 and 4.3 were obtained using STATA and are reported in Table 6.

Table 6: Allocative inefficiency of General Hospitals in Uganda by Region

\begin{tabular}{|c|c|c|c|c|c|}
\hline Region & $\begin{array}{l}\text { General } \\
\text { hospital }\end{array}$ & $\begin{array}{l}\text { Drugs \& med. } \\
\text { supplies }\end{array}$ & $\begin{array}{l}\text { employee } \\
\text { benefits }\end{array}$ & $\begin{array}{l}\text { Utilities } \begin{array}{r}\& \\
\text { consumables }\end{array} \\
\end{array}$ & $\begin{array}{l}\text { Average allocative } \\
\text { inefficiency }\end{array}$ \\
\hline \multirow[t]{5}{*}{ North } & Adjumani & 0.133 & 0.827 & 0.114 & 0.358 \\
\hline & Apac & 0.537 & 0.724 & 0.383 & 0.548 \\
\hline & Моyо & 0.085 & 0.944 & 0.090 & 0.373 \\
\hline & Nebbi & 0.157 & 0.043 & 0.184 & 0.128 \\
\hline & Kitgum & 0.050 & 0.000 & 0.028 & 0.026 \\
\hline Mean & & 0.192 & 0.508 & 0.160 & 0.287 \\
\hline \multirow[t]{7}{*}{ East } & Aturitur & 0.095 & 0.197 & 0.000 & 0.097 \\
\hline & Bugiri & 0.061 & 0.034 & 0.608 & 0.234 \\
\hline & Iganga & 0.192 & 0.094 & 0.116 & 0.134 \\
\hline & Kapchorwa & 0.000 & 0.123 & 0.546 & 0.223 \\
\hline & Moroto & 0.968 & 0.546 & 0.026 & 0.513 \\
\hline & Pallisa & 0.059 & 0.452 & 0.000 & 0.170 \\
\hline & Tororo & 0.072 & 0.709 & 0.219 & 0.333 \\
\hline \multirow[t]{2}{*}{ Mean } & & 0.207 & 0.308 & 0.216 & 0.243 \\
\hline & Bundibugyo & 0.089 & 0.033 & 0.034 & 0.052 \\
\hline \multirow[t]{4}{*}{ West } & Bwera & 0.465 & 0.226 & 0.354 & 0.348 \\
\hline & Kibale & 0.029 & 0.405 & 0.090 & 0.175 \\
\hline & Masindi & 0.094 & 0.125 & 0.121 & 0.113 \\
\hline & Kisoro & 0.795 & 0.792 & 0.000 & 0.529 \\
\hline \multirow[t]{2}{*}{ Mean } & & 0.294 & 0.316 & 0.120 & 0.243 \\
\hline & Kawolo & 0.131 & 0.073 & 0.081 & 0.095 \\
\hline \multirow[t]{4}{*}{ Central } & Mpigi & 0.672 & 0.139 & 0.074 & 0.295 \\
\hline & Mubende & 0.843 & 0.136 & 0.000 & 0.326 \\
\hline & Rakai & 0.650 & 0.865 & 0.133 & 0.549 \\
\hline & Kiboga & 0.079 & 0.076 & 0.043 & 0.066 \\
\hline Mean & & 0.475 & 0.258 & 0.066 & 0.319 \\
\hline \multirow[t]{2}{*}{ Overall mean } & & 0.292 & 0.348 & 0.141 & 0.273 \\
\hline & $\partial_{v}{ }^{2}$ & $-1.531 * * *$ & $1.647 * * *$ & $2.91 * * *$ & \\
\hline
\end{tabular}

138 | This work is licensed under a Creative Commons Attribution 4.0 International License. 
East African Journal of Interdisciplinary Studies, Volume 3, Issue 1, 2021

Article DOI: https://doi.org/10.37284/eajis.3.1.346

\begin{tabular}{|c|c|c|c|c|c|}
\hline Region & $\begin{array}{l}\text { General } \\
\text { hospital }\end{array}$ & $\begin{array}{l}\text { Drugs \& med. } \\
\text { supplies }\end{array}$ & $\begin{array}{l}\text { employee } \\
\text { benefits }\end{array}$ & $\begin{array}{l}\text { Utilities } \begin{array}{r}\& \\
\text { consumables }\end{array} \\
\end{array}$ & $\begin{array}{l}\text { Average allocative } \\
\text { inefficiency }\end{array}$ \\
\hline & $\partial u^{2}$ & -0.0079 & $1.356 * * *$ & $1.124 * * *$ & \\
\hline & $\partial$ & 0.0047 & 0.439 & 0.334 & \\
\hline & $\partial_{u}$ & 0.004 & 0.507 & 0.569 & \\
\hline & $\begin{array}{l}\gamma \\
X^{\wedge} 2(01)\end{array}$ & $\begin{array}{l}0.809 \\
4.659 * * *\end{array}$ & $\begin{array}{l}0.156 \\
4.38 * * *\end{array}$ & $\begin{array}{l}0.704 \\
8.7 * * *\end{array}$ & \\
\hline
\end{tabular}

$N B: * P<0.05, * * P<0.01$ and $* * * P<0.001$, the negative signs of ${ }^{\partial{ }^{2}} \&{ }^{2} u^{2}$ implies under reutilization

Half normal specification of allocative inefficiency term $\left(\mathrm{u}_{\mathrm{i}}\right)$ was selected using the procedure stated in Table 5. The estimated value of $\sigma^{2}$ is positive for the recurrent expenditures on two items; employee benefits and utilities and consumables and negative for drugs and medical supplies but statistically significant at a $1 \%$ level of significance for all the three. The significance level indicates that there is sufficient evidence to suggest that allocative inefficiencies are present in the data and that the differences between the observed (actual) and frontier (potential) costs are due to allocative inefficiency and not statistical noise alone. Theoretically, this implies that the estimated model and distributional assumptions for the error terms are appropriate. The negative variance means unfavourable or smaller proportions of recurrent expenditure and the positive variance means favourable expenditure.

Gamma $(\gamma)$ is the variance ratio, explaining the total variation in recurrent expenditures from the frontier level of costs attributed to allocative inefficiency. The estimated value of $\gamma$ (the ratio of the variance of recurrent expenditure due to allocative inefficiency i.e., $\left.\sigma_{u}^{2} /\left(\sigma_{u}^{2}+\sigma_{v}^{2}\right)\right)$ is 0.809 for the drugs and medical supplies, 0.156 for employee benefits and 0.704 for utilities and consumables. The interpretation is that if $\gamma \rightarrow 1$ it implies that more of the variation is attributed to allocative inefficiency and if $\gamma \rightarrow 0$ implies that more of the variation is due to statistical noise Aigner (1977). The findings clearly imply that the variation in the purchase of drugs and medical supplies $(\gamma=0.809)$ and utilities and consumables $(\gamma=0.704)$ are due to the allocative inefficiency of general hospitals and employee benefits $(\gamma=0.156)$ is due to statistical noise. The allocative inefficiencies of general hospitals were got by getting the means of predicted $\mathrm{u}$ value from SFA model fitted to STATA and is explained below.

In Table 6, along the rows show each general hospital's allocative inefficiency disaggregated into that portion experienced through the purchase of drugs and medical supplies, hire of labour input and payment for utilities and consumables. In the northern region, the most allocatively inefficient general hospital is Apac (0.548) followed by Moyo (0.373) and Adjumani (0.358). The results show that payments for employee benefits contribute highly towards allocative inefficiency, that is; Moyo (0.944), Adjumani (0.827) and Apac (0.724). Overal, in the Northern region, general hospitals are 28.7 percent allocatively inefficient. Of this 50.8 percent arises from payment for employee benefits, 19.2 percent due to purchase of drugs and medical supplies and 16 percent due to payment for utilities and consumables. It should also be noted that the least allocatively inefficient general hospital in the North is Kitgum (0.026) and it has an optimum allocation towards employee benefits.

In the Eastern region, the most allocatively inefficient general hospital is Moroto (0.513), followed by Tororo (0.333). This inefficiency is such that for Moroto, it's due to the purchase of drugs and medical supplies (0.968) and for Tororo due to payments for employee benefits (0.709)

139 | This work is licensed under a Creative Commons Attribution 4.0 International License. 
(Table 6). However, in overall, the general hospitals in the Eastern region are 24.4 percent allocatively inefficient. Of which 30.8 is due to payment for employee benefits.

In the western region, the most allocatively inefficient general hospital is Kisoro general hospital (0.529) followed by Bwera (0.348). For Kisoro this is due to the purchase of drugs and medical supplies (0.795) and payment for employee benefits (0.792) and for Bwera, it's due to the purchase of drugs and medical supplies (0.465) (Table 6). Overall, general hospitals in the western region are 24.3 percent allocatively inefficient. Of this, 31.6 percent is due to payment for employee benefits.

In the central region, the most allocatively inefficient general hospital is Rakai (0.549) due to payment for employee benefits (0.865). This is followed by Mubende (0.326) highly resulting from the purchase of drugs and medical supplies (0.843) (Table 6).

Nationally, the general hospitals in Uganda are 26 percent allocatively inefficient. Of this 34.8 percent is due to payment for employee benefits, 29.2 percent due to purchase of drugs and medical supplies and 14.1 percent due to payment for utilities and consumables.

Generally, one can notice that; the main source of allocative inefficiency is payments for employee benefits. That is, 15 out of 22 general hospitals (68\%) are allocatively inefficient when paying employee benefits. This is closely followed by allocative inefficiency arising from the purchase of drugs incurred by 10 out of the 22 general hospitals (45\%) and lastly due to payments for utilities and consumables where 7 out of 22 general hospitals (31\%) are allocatively inefficient.

The negative values of $\partial_{v}{ }^{2}$ and ${ }^{\partial_{u}{ }^{2}}$ means that variations due to both general hospital characteristics which are normally and identically distributed about the mean and those that arise randomly due to allocative inefficiency are below optimum. It leads to unfavourable allocations or under budgeting or unfavourable use of hospital resources.

\section{DISCUSSION, CONCLUSIONS AND POLICY RECOMMENDATIONS}

\section{Discussion}

The magnitude of hospital operational costs and poor delivery of healthcare raise questions about the inefficiency of general hospitals. The results in this study confirm that general hospitals are not allocatively efficient. There is statistically significant evidence that general hospitals in three regions of Northern, Eastern and Western Uganda face inefficiency in the use of hospital funds when paying for labour input. Allocative inefficiency on average was 0.508 in the North, 0.308 in East and 0.316 in West, arising from the hire of labour force.

These findings are similar to the findings by Rodríguez-Álvarez et al. (2004) in the Spanish Public Hospitals. They found out that the proportion in which care graduates were used was above optimum at (0.808). Similarly, other Public Organisations like Banks commit allocative inefficiency in about the same range. For example, a study by Brissimis et al. (2006), in the European Banking sector showed that allocative inefficiency was in the range of 1.52 percent to 14.56 percent in favour of hire of labour as compared to other factors. In African countries, for example, labour costs are between 33 and 79 percent of the total expenditures of public hospitals. Similarly, WHO (2004); reported that in Indonesian hospitals' personnel costs are about 40 percent of total expenditures, and in Jamaica and Belize, personnel costs range from about 50 percent to 74 percent of total hospital expenditures. In China, labour costs are between 23 and 26 percent of total expenditures. In Uganda according to a briefing paper by the Ministry of Health (MOH, 2017) on key issues for 
health delivery, human resources cover 60 percent of the healthcare budget, of which 38 percent was spent on General Hospitals.

This compares favourably with the findings of this study where 15 out of 22 general hospitals (68 percent) hired more labour inputs with inefficiency values ranging between 0.123 and 0.944 , seven out of the 22 general hospitals ( 31 percent) preferred the use of more drugs and medical supplies with allocative inefficiency value ranging between 0.131 and 0.986 and 10 out of 22 general hospitals (45 percent) paid more on utilities and consumables with inefficiency values ranging between 0.114 and 0.608 . The fear is that the labour mix hired may not be relevant to the production of health care services because it's dominated by other employees (nonmedical staff).

\section{Conclusions}

From the findings one can conclude that;

- Allocative inefficiency affects all general hospitals studied in various intensities. Implying that each general experience allocative inefficiency in one way or the other. However, from the three key expenditure areas, it's clear that the sector experiences up to 34.8 percent inefficiency through expenditure on employee benefits, 14.1 percent inefficiency through payments of utilities and consumables and 29.2 percent in purchase of drugs.

- Some general hospitals showed an optimal allocation (with allocative inefficiency equal to 0.000) in some uses of hospital finances. For example, Aturitur, Pallisa, Kisoro and Mubende made optimal allocations to utilities and consumables. Only Kitgum made optimal allocations to employee benefits and only Kapchorwa made optimal allocations to drugs and medical supplies.

\section{Recommendations}

For policy purposes, the research recommends that, for the portion of inefficiency attributed to payment of employee benefits (0.348), general hospital or government can control this by;

Improving the process of hire of labour by for example limiting the use of other employees. On average, a general hospital employee up to 65 other employees to clean wards, slash, trim fences, sweeping compounds and maintain flower gardens. Some of them can be replaced by light machines like mowers and washing machines. For allocative inefficiency due to payments of utilities and consumables (0.141), the general hospital can;

- Reduction in costs of electricity can be through control of lighting in the hospital by say removing or reducing some lights. Reduction of the number of bulbs in multiple light fixtures, eliminating unneeded lighting in areas where lights need not be all the time like hospital corridors and walkways and or install solar panels as a way of cost-cutting and Use timers to heat coffee pots water instead of hot plates.

- Water wastage can be reduced by replacing inefficient sinks, toilets and urinals and fit those with low flow models. One can also dig VIP pit latrines.

The other source of inefficiency is the purchase of drugs (0.292). The study recommends the use of the pharmacy department to manage purchasing and monitor delivery of drugs, through the hospital drug and therapeutics committee. This committee can, monitor medicine selection, procurement, distribution and use through the education of staff and patients. 


\section{REFERENCES}

Aigner, D., Lovell, C. K., \& Schmidt, P. (1977). Formulation and estimation of stochastic frontier production function models. Journal of econometrics, 6(1), 21-37.

Baltagi, B. H. (2005). Econometric Analysis of Panel Data. 2nd Ed. New York: John Wiley \& Sons.

Battese, G. E., \& Coelli, T. J. (1995). A model for technical inefficiency effects in a stochastic frontier production function for panel data. Empirical economics, 20(2), 325-332.

Brissimis, S. N., Delis, M. D., \& Papanikolaou, N. I. (2008). Exploring the nexus between banking sector reform and performance: Evidence from newly acceded EU countries. Journal of Banking \& Finance, 32(12), 2674-2683.

Caballer-Tarazona, M., Moya-Clemente, I., VivasConsuelo, D., \& Barrachina-Martínez, I. (2010). A model to measure the efficiency of hospital performance. Mathematical and computer modelling, 52(7-8), 1095-1102.

Carey, K. (1997). A panel data design for estimation of hospital cost functions. Review of Economics and Statistics, 79(3), 443-453.

Choi, J. H., Fortsch, S. M., Park, I., \& Jung, I. (2017). Efficiency of US hospitals between 2001 and 2011. Managerial and Decision Economics, 38(8), 1071-1081.

Eakin, B. K. (1991). Allocative inefficiency in the production of hospital services. Southern Economic Journal, 58(1), 240-248.

Greene, W. H. (2003). Econometric analysis. Pearson Education India.

Hamidi, S. (2016). Measuring efficiency of governmental hospitals in Palestine using stochastic frontier analysis. Cost Effectiveness and Resource Allocation, 14(1), 1-12.

Jondrow, J., Lovell, C. K., Materov, I. S., \& Schmidt, P. (1982). On the estimation of technical inefficiency in the stochastic frontier production function model. Journal of econometrics, 19(2-3), 233-238.

Kumbhakar, S. C., \& Lovell, C. K. (2003). Stochastic frontier analysis. Cambridge university press.

Lave, J. R., \& Lave, L. B. (1984). Hospital cost functions. Annual Review of Public Health, 5(1), 193-213.

Meeusen, W., \& van Den Broeck, J. (1977). Efficiency estimation from Cobb-Douglas production functions with composed error. International economic review, 18(2), 435-444.

MOH (2017). Statistical Review of Progress to Inform the Mid-Term Review of the Uganda Health Sector Development Plan 2015/20162019/2020. Kampala, UG: Ministry of Health.

Mujasi, P. N., \& Kirigia, J. M. (2016). Productivity and efficiency changes in referral hospitals in Uganda: An application of Malmquist total productivity index.. Health Systems and Policy Research, 3(128), 1-12.

Mutter, R. L., Rosko, M. D., \& Wong, H. S. (2008). Measuring hospital inefficiency: the effects of controlling for quality and patient burden of illness. Health Services Research, 43(6), 19922013.

Nabukeera, M. S. (2016). Challenges and barriers to the health service delivery system in Uganda. IOSR Journal of Nursing and Health Science, 5(2), 20-38.

Nannyonjo, J., \& Okot, N. (2013). Decentralisation, local government capacity and efficiency of

142 This work is licensed under a Creative Commons Attribution 4.0 International License. 
health service delivery in Uganda. Journal of African Development, 15(1), 125-158.

O'Donnell, C. J., \& Nguyen, K. (2011). Review of efficiency measurement methodologies to inform hospital resource allocation decisions in NSW. An Evidence Check Rapid Review Brokered by the Sax Institute for the NSW Treasury.

Peacock, S., Chan, C., Mangolini, M., \& Johansen, D. (2001). Techniques for measuring efficiency in health services. Productivity Commission: Staff Working Paper. Belconnen, ACT: Commonwealth of Australia.

Rodríguez-Álvarez, A., Fernández-Blanco, V., \& Lovell, C. K. (2004). Allocative inefficiency and its cost:: The case of Spanish public hospitals. International Journal of Production Economics, 92(2), 99-111.

Uganda Statiscal abstract (2017/18); Uganda Health Accounts

Wei, Y., Yu, H., Geng, J., Wu, B., Guo, Z., He, L., \& Chen, Y. (2018). Hospital efficiency and utilisation of high-technology medical equipment: A panel data analysis. Health policy and technology, 7(1), 65-72.

WHO. (2004). Developing Health Management Information Systems: A Practical Guide for Developing Countries. Geneva: World Health Organization.

Worthington, A. C. (2004). Frontier efficiency measurement in health care: a review of empirical techniques and selected applications. Medical care research and review, 61(2), 135-170.

Yawe, B. (2010). Hospital performance evaluation in Uganda: a super-efficiency data envelope analysis model. Zambia Social Science Journal, 1(1), 79-105.
Yawe, B. L. \& Kavuma, S. N. (2008). Technical efficiency in the presence of desirable and undesirable outputs: a case study of selected district referral hospitals in Uganda. Journal of Health Policy and Development, 6 (1), 37-53.

Yawe, B. L. (2006). Technical efficiency and total factor productivity growth in Uganda's district referral hospitals. Doctoral dissertation. University of Dar es Salaam.

Yong, K., \& Harris, A. H. (1999). Efficiency of hospitals in Victoria under casemix funding: a stochastic frontier approach. Australia: Centre for Health Program Evaluation.

143 | This work is licensed under a Creative Commons Attribution 4.0 International License. 